\title{
Um breve olhar sobre o sistema de canais da Baixada Campista
}

\author{
Alan Carlos Vieira Vargas ${ }^{1}$ \\ Rodrigo Torres Lima ${ }^{2}$ \\ Roger Rangel Coutinho ${ }^{3}$ \\ Sergio Otávio de Souza ${ }^{4}$ \\ ${ }^{1}$ Instituto Federal de Educação, Ciência e Tecnologia Fluminense - IFF \\ Rua Dr. Siqueira, 273 - Parque Dom Bosco \\ Campos dos Goytacazes, RJ - CEP 28030-130 \\ ${ }^{2}$ Instituto Federal de Educação, Ciência e Tecnologia Fluminense - IFF \\ Rua Dr. Siqueira, 273 - Parque Dom Bosco \\ Campos dos Goytacazes, RJ - CEP 28030-130 \\ ${ }^{3}$ Instituto Federal de Educação, Ciência e Tecnologia Fluminense - IFF \\ Rua Dr. Siqueira, 273 - Parque Dom Bosco \\ Campos dos Goytacazes, RJ - CEP 28030-130 \\ ${ }^{4}$ Instituto Federal de Educação, Ciência e Tecnologia Fluminense - IFF \\ Rua Dr. Siqueira, 273 - Parque Dom Bosco \\ Campos dos Goytacazes, RJ - CEP 28030-130
}

\begin{abstract}
This paper describes the historical context of Baixada Campista's channels, in the finish of the XIX century, and first beginning of the XX century. Brazilian government wus formulation of a public politics for wetlands because this lands has epedimies more agricultural areas, mainly after the creation of DNOS (National Department of Works and Sanitation) in 1936. The construction of 1400 kilometers channels in the Baixada Campista, where services of cleaning were accomplished with dredges, embankments, and rectifications of rivers, and mainly the opening of channels. Fact that promoted a deep transformation in the dynamics of the ecosystems of the end of Paraiba river area. This paper analise the process of evolution and the construction of Baixada Campista's channels, and the historical context this greats intervetions. It follows describing the conflicts results of economic use of water, and conclusion propose a new model of public gestion of use water.
\end{abstract}

Palavras-chave: DNOS, canais, conflito, gestão, Baixada Campista.

\section{1 - Introdução}

A região denominada Baixada Campista ou dos Goytacazes, estende-se desde a Foz do Rio Macaé até a foz do Rio Paraíba do Sul, abrangendo cinco municípios: São Francisco do Itabapoana; São João da Barra; Campos dos Goytacazes; Quissamã; Carapebus; e Conceição de Macabu (WEBER, 2001).

Esta região era formada por diversos rios e centenas de lagoas, brejos e canais perenes e sazonais. No período de maior precipitação pluvial, os corpos hídricos transbordam, inundando as planícies adjacentes e ampliando o espelho d'águas de mais de uma centena de lagoas, interligadas por uma complexa malha de canais e brejos rasos. Nos períodos de altos índices pluviométricos de setembro a janeiro, somados a pouca declividade dos terrenos criase as condições favoráveis à inundação.

Não só as multiplicadas lagoas, e rios [...], fecundam de águas estas terras, como ainda outros muitos, cujas origens, ou procedem logo da sua a celebrada Lagoa Feia, ou da concorrência de muitos córregos, e brejais, que [...] têm entre si uma recíproca correspondência, pela qual se engrossam, e se constituem rios (COUTO REIS, 1785 apud SOFFIATI NETO, 1996) 
Rios, canais, lagoas e brejos formavam imenso pantanal e, assim, permaneciam vários meses, e só ocorria à drenagem quando as forças das águas descarregadas da lagoa Feia por um sistema de canais e concentradas em uma lagoa na restinga rompiam a faixa de areia escoando para o mar o volume excedente acumulado (BIDEGAIN; BIZERRIL; SOFFIATI NETO, 2002). Características estas que diante da visão sanitarista do final do século XIX e início do XX serviram de justificativa e força motriz para as grandes intervenções promovidas pelo DNOS, no sistema hídrico natural da Baixada Campista (MELLO e VALPASSOS, 2007).

\section{2 - As grandes obras, um breve histórico.}

No final século XIX, o aporte das novas tecnologias agroindústrias como as máquinas a vapor advindas da Europa tornaram possível a transformação das pequenas unidades produtivas (engenhos de açúcar) em grandes usinas. Estas necessitavam de grandes áreas produtivas para manter seu parque industrial em atividade plena, fato que levou a um processo intenso de ampliação das terras agricultáveis, e o consequente avanço sobre as lagoas, zonas alagadiças e brejos. Neste contexto, foram criadas sucessivas comissões de saneamento, e órgãos responsáveis pelos estudos e obras da Baixada Campista (Quadro 1).

Quadro 1 - Entidades responsáveis por estudos e obras hidráulicas a partir de 1894

\begin{tabular}{|l|l|l|}
\hline Entidade & Subordinação & Período \\
\hline $\begin{array}{l}\text { Comissão de Estudos e Saneamento da } \\
\text { Baixada do Estado do Rio de Janeiro }\end{array}$ & Governo Fluminense & $1894-1901$ \\
\hline $\begin{array}{l}\text { Comissão do Porto de São João da Barra e } \\
\text { Baixada do Nordeste do Estado do Rio de } \\
\text { Janeiro }\end{array}$ & $\begin{array}{l}\text { Inspetoria Federal de } \\
\text { portos, costas e vias } \\
\text { navegáveis. }\end{array}$ & 1912 \\
\hline Comissão do canal de Campos a Macaé & $\begin{array}{l}\text { Inspetoria Federal de } \\
\text { portos, costas e vias } \\
\text { navegáveis. }\end{array}$ & 1918 - 1925 \\
\hline $\begin{array}{l}\text { Comissão de Estudos e Obras contra as } \\
\text { inundações da Lagoa Feia e Campos de } \\
\text { Santa Cruz }\end{array}$ & $\begin{array}{l}\text { Inspetoria Federal de } \\
\text { portos, costas e vias } \\
\text { navegáveis. }\end{array}$ & 1925 - 1928 \\
\hline Escritório Saturnino de Brito & $\begin{array}{l}\text { Governo Fluminense } \\
\text { Diretoria de obras } \\
\text { públicas. }\end{array}$ & $1925-1930$ \\
\hline $\begin{array}{l}\text { Comissão de Saneamento da } \\
\text { Baixada Fluminense }\end{array}$ & Governo Federal & $1933-1940$ \\
\hline $\begin{array}{l}\text { Dep. Nacional de Obras de Saneamento - } \\
\text { DNOS }\end{array}$ & Governo Federal & 1989 \\
\hline
\end{tabular}

Fonte: Adaptado de BIDEGAIN; BIZERRIL; SOFFIATI NETO (2002).

A Comissão de Estudos e Saneamento da Baixada do Estado do Rio de Janeiro realizou as obras: de limpeza do rio Macabu (1894); de construção do canal de Jagoroaba, para escoar as águas da Lagoa Feia para o oceano (1896-97); de desobstrução do canal Campos - Macaé (1897- 1901), suspensa por portaria; de restabelecimento da largura de 11 metros do rio Carrapato, numa extensão de 66 quilômetros; de restabelecimento parcial de 13,5 km canal de S. Bento ou do Frade (1897-1900); de limpeza dos sangradouros da lagoa Feia, com reabertura da vala do Furado (início em 1897); de trabalhos análogos entre a lagoa Feia e de Dentro e de levantamentos topográficos em toda a região.

A Comissão do Porto de S. João da Barra e Baixada Noroeste do Estado do Rio de Janeiro elaborou a planta de $19 \mathrm{~km}$ do rio Paraíba do Sul, fixou referência de nível com base em observações maregráficas e dragou, sem sucesso, sua barra principal no Atlântico, além de desobstrui os sangradouros da Lagoa Feia. 
A Comissão do Canal de Macaé a Campos realizou estudos topográficos e batimétricos, traçou seções transversais e instalou várias réguas para leitura do nível de água, além de promover o rebaixamento do leito e a limpeza de vários trechos do canal Campos - Macaé, e também a desobstrução dos rios: Novo, Barro Vermelho, Furado, Andreza e Caxexa, dentre outras obras.

A Comissão de Estudos e Obras contra Inundações da Lagoa Feia e Campos de Santa Cruz, após reunir e analisar os dados produzidos pelas comissões precedentes, concluiu que de todo o acervo herdado, pouco seria aproveitável. Reiniciou a limpeza dos sangradouros da lagoa Feia (51 km lineares) e a propôs a criação de um vertedouro único para desaguá-la no mar. Nestas premissas, em contraponto a hipótese de Saturnino de Brito, de que seria mais eficaz manter conservados os sangradouros da Lagoa Feia do que jogar as águas nas costas de um único canal, o Canal de Jagoroaba, o fardo de escoar as suas águas para o oceano. Foi construído na década de 40, o Canal das Flechas, que passou a desempenhar este papel.

O Escritório Saturnino de Brito realizou entre 1925 e 1930, o que é considerado tecnicamente os estudos mais completos sobre o rio Paraíba do Sul e a Lagoa Feia, o "Relatório sobre o Melhoramento do rio Paraíba e Lagoa Feia”.

A Comissão de Saneamento da Baixada Fluminense possuía como escopo específico: levantar a documentação produzida pelas comissões anteriores; verificar até que ponto houve execução das obras projetadas e manutenção das mesmas; investigar as causas responsáveis pelo malogro de iniciativas com vistas ao saneamento; formular um programa global que permitisse o saneamento da baixada campista visando incorporação de terras ao processo produtivo; inventariar os recursos materiais disponíveis para a execução de obras e de apresentar relação de material a ser adquirido e orçar os trabalhos a serem executados. Tudo isto objetivando o então considerado caos, mitigando os riscos a economia local e a saúde pública. Esta comissão foi posteriormente transformada em Diretoria de Saneamento da Baixada Fluminense, realizando diversas obras, das quais se destacam as expostas no quadro 2 a seguir.

Quadro 2: Serviços executados pela Diretoria de Saneamento da Baixada Fluminense na Baixada Campista

\begin{tabular}{|l|c|}
\hline Obra & Extensão (Km) \\
\hline Limpeza de cursos d’água & 800 \\
\hline Conservação de cursos d'água & 865 \\
\hline Construção manual de cursos d'água & 320 \\
\hline Dragagem de canais & 19 \\
\hline Construção de dique de alvenaria & 15,5 \\
\hline Construção de dique de terra & 7,6 \\
\hline
\end{tabular}

Fonte: Adaptado de BIDEGAIN; BIZERRIL; SOFFIATI NETO (2002).

O DNOS, criado pelo Decreto-Lei $\mathrm{n}^{0}$ 2.367, de 4 de julho de 1940, em pleno EstadoNovo, foi reorganizado em 1946 (Decreto-Lei $n^{\circ}$ 8.847, de 24 de Janeiro), reestruturado em 1962 pela Lei no 4.089, de 13 de junho, e extinto em 1989, no início do Governo Collor. Teve papel marcante no processo de saneamento da Baixada campista.

Da sua criação até 1950, o DNOS, promoveu um grande número de obras, que impressionavam tanto pela quantidade, quanto pela complexidade das mesmas, podendo ser denominadas como obras de grande vulto para época, tais como: $18 \mathrm{Km}$ de diques de alvenaria de pedra argamassa na margem direita do rio Paraíba do Sul, entre Itereré e a cidade de Campos; $26 \mathrm{Km}$ de dique de terra a jusante da cidade; dragagem de $221 \mathrm{KM}$ de canais e a construção do canal das Flechas, ligando a Lagoa Feia ao oceano atlântico, com seus $13 \mathrm{Km}$ de extensão, e $120 \mathrm{~m}$ de largura, que substituiu o escoamento natural realizado pelos rios da onça, Novo, do Ingá, do Barro Vermelho, e do Furado, que confluíam para o Rio Iguaçu (BIDEGAIN; BIZERRIL; SOFFIATI NETO, 2002). 
Deste de então, o DNOS, trabalhou arduamente na tentativa de cumprir sua hercúlea missão, a de "domesticar o ambiente hostil”" conforme as palavras de Getulio Vargas.

\begin{abstract}
Há no Brasil, três problemas fundamentais, dentro dos quais, está triangulado o seu progresso: sanear, educar, povoar. O homem é produto do habitat. Disciplinar a natureza é aperfeiçoar a vida social. Drenar pântanos, canalizar as águas para as zonas áridas, transformando-as em celeiros fecundos, é conquistar a terra. Combater as verminoses, as endemias, as condições precárias de higiene, é criar o cidadão capaz e consciente. Sanear, educar, povoar - eis a palavra de ordem, cuja difusão e cumprimento devem presidir o grande projeto da 'valorização do capital humano (VARGAS, 1938).
\end{abstract}

Impondo ao espaço natural uma "ordem” artificial sintonizada com os interesses das usinas de açúcar, dentro do contexto da época a concepção da intervenção na natureza visava resgatar o caráter público do bem natural, diferente do atual conceito de sustentabilidade ambiental, fato que conforme provado pelo tempo, foi motivo de inúmeros problemas, e limitações de uso. Mesmo assim até sua extinção o DNOS cortou a baixada campista com cerca de $1.400 \mathrm{Km}$ de canais. Sendo consideradas tamanhas as suas proezas, que o mesmo passou a possuir uma conotação quase mítica (SOFFIATI NETO, 2005). Levando-o alçar a posição de autarquia federal, com total autonomia financeira e administrativa, financiadas por fundo próprio, sendo que o artigo 46 da Lei Federal 4.089/62 definia e demonstrava o tamanho do poder delegado ao DNOS.

Pertencem à União e ficam sob a jurisdição do DNOS, que poderá aforá-los ou aliená-los, os acrescidos de terrenos de marinha resultantes de obras realizadas pelo DNOS, bem como os recuperados nas margens dos rios, canais e lagoas, que por qualquer título não estejam no domínio particular (SOFFIATI NETO, 2005).

\title{
3 - Os conflitos de uso
}

No caso específico do sistema de canais da Baixada Campista, o conflito entre os diversos usuários dos sistemas, pode ser dividido em ao menos três vetores de interesse e de conflito: 1) as formas de uso que comprometem a disponibilidade de água; 2) as que degradam a qualidade da águas; 3) as relativas aos próprios mecanismos de controle de vazão. Dentro do novo sistema hídrico criado pelos canais, onde a drenagem natural ocorria sob a forma de empossamentos em lagoas perenes, lagoas sazonais e uma pequena capilaridade entre estes sistemas. A partir da construção do novo sistema de drenagem baseado em canais de vazão o gerenciamento das comportas passa a ser estratégico, o que obriga o funcionamento das vazões regulando os períodos de cheia com os de estiagem. (GETIRANA, 2005).

No antigo sistema de drenagem natural as lagoas e os brejos tinham um papel importante com criadouros naturais de piscicultura, surge também uma nova paisagem onde as cheias do Rio Paraíba não ocorrem mais por transbordamento, produzindo a fertilização das terras de massapé. Passando a prevalecer uma nova lógica onde a irrigação passa a ser forma de aumentar o caráter hídrico das terras agricultáveis.

Neste ínterim os conflitos de interesses entre os atores sociais usuários do sistema de canais da Baixada Campista eclodiu na década de 70, e permaneceu até os dias de hoje, conforme pode ser observado no quadro 3 , segundo sua ordem cronológica.

Quadro 3 - Cronologia dos principais conflitos entre atores sociais usuários do sistema de canais da Baixada Campista.

\begin{tabular}{|l|l|c|}
\hline Ocorrências & Atores em conflito & Ano \\
\hline & Dep. de Recursos & \\
$\begin{array}{l}\text { Questionamento sobre os impactos das obras da Baixada, } \\
\text { sobre os ecossistemas locais. }\end{array}$ & $\begin{array}{l}\text { Naturais Renováveis da } \\
\text { Séc. Est. de Agricultura } \\
\text { e Abastecimento \& }\end{array}$ & \multirow{2}{*}{1976} \\
\hline
\end{tabular}




\begin{tabular}{|l|l|l|}
\hline & DNOS & \\
\hline $\begin{array}{l}\text { Parecer técnico sobre o impacto ambiental das obras do } \\
\text { DNOS }\end{array}$ & FEEMA \& DNOS & 1979 \\
\hline $\begin{array}{l}\text { Pescadores de Ponta Grossa paralisam draga flutuante que } \\
\text { pretendia remover o controle hidráulico natural do nível da } \\
\text { Lagoa Feia, conhecido como durinho da valeta. }\end{array}$ & Pescadores \& DNOS & 1979 \\
\hline $\begin{array}{l}\text { Protesto dos pescadores de Farol de São Thomé, junto a canal } \\
\text { Quitinguta, pela imediata ligação do mesmo com mar, caso } \\
\text { que ficou conhecido com buraco do ministro. }\end{array}$ & Pescadores \& DNOS & 1979 \\
\hline $\begin{array}{l}\text { Pecadores da Lagoa do Campelo arrancam as comportas do } \\
\text { Canal Cataia. }\end{array}$ & Pescadores \& DNOS & 1980 \\
\hline
\end{tabular}

Fonte: Adaptado de (CARNEIRO, 2007).

Cabe ressaltar que a mola mestra destes conflitos, era a forma diferenciada de tratamento dos atores sociais, em quanto os grandes proprietários rurais eram ouvidos, e na maioria das vezes eram acatadas suas reivindicações, os pescadores eram ignorados, sobrando a eles apenas a negociação via confronto direto.

A forma como ocorreu à extinção do DNOS, no final da década de 80 pelo governo Collor, esta dentro do contexto político do neoliberalismo, onde o estado mínimo era a nova ordem política. A extinção cria um vácuo de gestão do sistema de canais, somado aos conflitos dos usuários do sistema de canais da Baixada Campista.

\section{4 - O Fim do Departamento Nacional de Obras e Saneamento - DNOS: os canais sob nova gestão}

O poderoso departamento, criado em 04 de julho de 1940, através do Decreto-Lei no 2.367, teve o auge de suas ações no início dos anos setenta. Na década de 70 também começaram os primeiros embates com ecologistas que tentavam, de todas as maneiras possíveis, fazer a defesa do patrimônio natural. Na década de 80 , já não possuindo a mesma pujança orçamentária dos tempos idos, o DNOS acabou por ser extinto (fato ocorrido em 13 de junho de 1989, no início do governo Collor). A partir daí, passar a valer a lei do interesse particular e a vontade daqueles que possuíam maior capacidade de articulação. Sendo notória a afirmativa do então presidente da organização não governamental Centro Norte Fluminense para Conservação da Natureza - CNFCN, "ruim com o DNOS, pior sem ele. Agora não temos nem a quem recorrer”.

Após a promulgação da Lei 9.433, em 1997, que instituiu a Política Nacional de Recursos Hídricos, e a formalização dos instrumentos de gestão e dos e organismos de bacia, a Secretaria de Infraestrutura Hídrica do Ministério de Integração Nacional, herdeira patrimonial do DNOS, voltou novamente sua atenção para os canais da Baixada Campista. Já em 2000, iniciaram-se as tratativas com o Governo do Estado do Rio de Janeiro, no sentido de se delegar competências ao Poder Público Estadual objetivando a reavaliação do sistema e a priorização de obras de recuperação. Em 2004, a Agência Nacional de Águas firmou convênio com a Superintendência Estadual de Rios e Lagoas - SERLA, delegando-lhe as competências de analisar e de emitir documentos de outorga de direito de uso dos recursos hídricos nos canais da Baixada Campista. Em 2006, foi a vez do Ministério de Integração Nacional que celebrou convenio com a SERLA a fim de propiciar a transferência de recursos financeiros para a elaboração de um plano de recuperação e operação do referido sistema de drenagem. Em 2007, o Governo Estadual propôs a criação de comitês de bacias hidrográficas, tendo como base o recorte territorial estabelecido pelo Conselho Estadual de Recursos Hídricos, que definiu 10 novas Regiões Hidrográficas no Estado do Rio de Janeiro.

Assim Reconhecendo a complexidade e a possível demora do processo de mobilização para criação de um organismo de bacia em uma área do porte da RH-09, e considerando a 
necessidade premente de se intervir, de maneira emergencial muitas das vezes, em pontos críticos do sistema, e considerando, por último, a sinalização do Governo Federal em disponibilizar, imediatamente, recursos financeiros para custear tais intervenções, a Presidência da SERLA decidiu criar o Grupo de Articulação Institucional - GAI. O GAI foi formado com parcerias firmadas com municípios e representantes da sociedade civil organizada, e resultou da pressão de usuários aflitos com o abandono dos canais que provocaram prejuízos repetitivos em suas áreas de produção. O caráter provisório deste Grupo prendeu-se ao propósito de levantamento, análise, discussão, priorização e encaminhamento a SERLA, de propostas de intervenção para serem custeadas pelo Governo Federal. Desta forma, o período de existência do GAI estaria limitado à institucionalização do Comitê de Bacias Hidrográfica da RH-09 (SERLA, 2007).

\section{5 - Conclusões e resultados}

Tendo em vista a relevância do sistema de canais da Baixada Campista para a atual estrutura ambiental da região, e dentro da nova política nacional de recursos hídricos, e também a longevidade dos conflitos existentes, faz-se necessário uma análise pormenorizada da questão. Análise esta que necessita ter como parâmetro indelével a satisfação dos interesses e necessidades diversas, e que sejam alicerçadas em mecanismos de tomada de decisão que funcionem de forma análoga aos utilizados pelos gestores da iniciativa privada, que embora sejam capazes de mensurar e avaliar os diversos interesses em jogo, não se deixam influenciar pelos mesmos. Balizando assim a tomado de decisão em dados e informações puramente técnicas, e comprovadamente incontestáveis.

Neste contexto podemos traçar a hipótese de que o sistema de canais da Baixada Campista pode ser tratado como produto/serviço, fornecido aos consumidores/usuários, que como tal devem ser abastecidos na qualidade e quantidade que demandam (KOTLER; JATUSRIPITAK; MAESINCEE, 1997). Para tal pleito qualquer modelo de tomada de decisão necessita levar em conta algumas questões para configuração dos parâmetros de tomada de decisão: Quem são os usuários? Qual a demanda quantitativa e qualitativa de cada usuário? Qual o valor percebido pelo usuário por este serviço? Qual o retorno econômico e social retornado por cada usuário, em relação a investimento realizado? Qual o uso mais relevante para a sociedade como um todo? Qual o custo-benefício e o custo-efetividade da manutenção do sistema? E qual os impactos ambientais, sociais e econômicos do sistema?

Assim sendo, é de suma importância destacar, que em sistema complexos como o sistema em epigrafe a livre negociação de interesses, em voga, nos conselhos e comitês gestores, não se mostra eficiente, já que os valores de mediação e negociação assumem vetores multidimensionais, difíceis de elencar, mensurar e parametrizar (GETIRANA, 2005). Nestas premissas elaboramos, a partir da análise empírica dos conflitos de uso, entre os diversos atores usuários do sistema de canais da baixada, um modelo simplificado em forma de diagrama (figura 1). Sobre o qual cabe esclarecer sua limitação de representar os atores sociais, suas demandas e retornos de investimentos. 


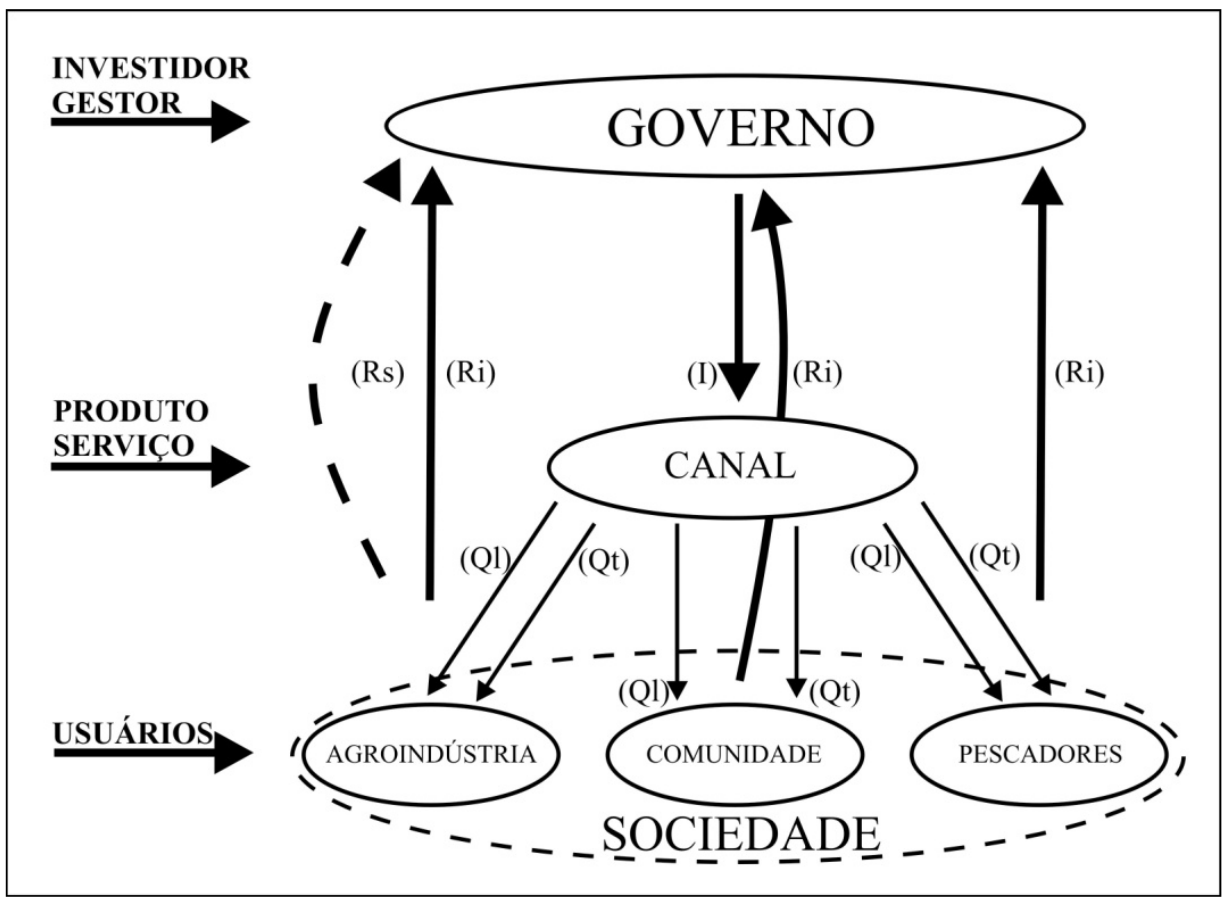

Figura 1 - Modelo de análise para tomada de decisão (investimento x retorno)

Fonte: elaborado pelos autores

O modelo de retorno $x$ investimento pode ser aplicado na análise e tomada de decisão, considerando as seguintes formulas:

Sendo: RIG = retorno do investimento para o governo; $\mathrm{I}=$ investimento; $\mathrm{Ri}=$ retorno individual dos usuários; $\mathrm{Rs}$ = retorno da social; $\mathrm{Ql}$ = qualidade; $\mathrm{Qt}$ = quantidade; Temos:

$\mathrm{I}=\sum_{i=1}^{n}(Q l . Q t)_{i} \quad$ (o volume de investimento diretamente a proporcional ao produto da

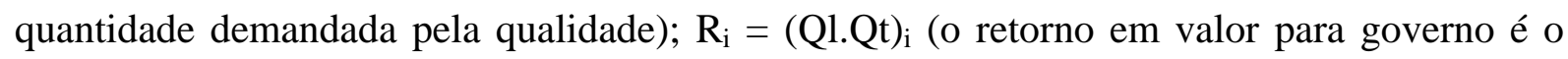
produto da quantidade pela qualidade demandada por cada usuário);

$R s=\sum_{i=1}^{n} R_{i}+\mathrm{K}$ (onde K é índice de melhoramento na qualidade do sistema); Resultando em: $\mathrm{RIG}=\sum_{i=1}^{n}(Q \mathrm{l} \cdot \mathrm{Qt})_{i} \pm \sum_{i=1}^{n} R_{i} \cdot \mathrm{K}$

Assim sendo o valor do retorno, pode ser negativo, caso o investimento não seja capaz produzir o serviço na quantidade e qualidade desejadas pelos usuários, ou esteja ocorrendo uma continua degradação dos serviços, tornando $K<1$. Pode ser nulo quando os investimentos geram o serviço na quantidade e qualidade exata desejada pelos usuários. E pode ser positivo, no caso de investimentos contínuos que promovam melhorias nos serviços, e façam $\mathrm{K}>1$.

Também mister salientar que a análise em questão tanto pode ser realizada com base no retorno global (RIG), quanto analisada, sobre os retornos individuais (Ri), objetivando o norteamento das negociações, quando não for possível satisfazer toda a demanda.

Outro aspecto importante, é que embora os investimentos sejam facilmente mensuráveis, já que se tratam de valores financeiros, os retornos podem ser de diversas origens: financeiros (impostos); qualidade de vida (IDH); recuperação ambiental; saúde; aprovação do governo. Desta forma o modelo necessita ser abastecido com informações de diversas fontes, para que seja possível a avaliação retorno $x$ investimento, ou poderíamos chamá-la de custo $x$ efetividade, tendo em vista a há uma relação entre valores monetários e não monetários, conforme esclarece Cohen e Franco (2004). 
Desta forma tendo em vista a importância dos sistemas de canais da Baixada Campista e complexidade dos conflitos envolvidos, cabe ressaltar que a análise destas questões deve levar em conta não apenas critérios ecológicos, mas também critérios voltados para a gestão estratégica deste recurso.

\section{Referências}

BIDEGAin, Paulo B. da S. P; BIZERRIL, Carlos R. S. F.; SOFFIATI NETO, A. A. Lagoas do Norte Fluminense - perfil ambiental. Rio de Janeiro: SEMADS, 2002.

CARNEIRO, Paulo Roberto Ferreira. Água e Conflito na Baixada dos Goytacazes. Disponível em: http://www.abep.nepo.unicamp.br/site_eventos_abep/pdf/abep2004_825.pdf. Acesso em 03 nov. 2007.

COHEN, Ernesto; FRANCO, Rolando. Avaliação de projetos sociais. Petrópolis, RJ: Vozes, 2004.

GETIRANA, Augusto César Vieira. Análise de soluções de conflitos pelo uso da água no setor agrícola através de técnicas de programação linear. Rio de Janeiro: UFRJ, 2005. Dissertação (Mestrado) COPPE/UFRJ, Rio de Janeiro, 2005. Disponível em: http://wwwp.coc.ufrj.br/teses/mestrado/ rh/2005/teses/getirana_acv_05_t_m_rhs. pdf . Acesso em: 03 nov 2007.

KOTLER, Philip; JATUSRIPITAK, Somkid; MAESINCEE, Suvit. O Marketing das nações: Uma abordagem estratégica para construir as riquezas nacionais. São Paulo: Futura, 1997.

MELLO, Marco Antônio da Silva; VALPASSOS, Carlos Abraão Moura. O saneamento do Brasil: Seus efeitos sobre a pesca artesanal e o manejo dos ecossistemas da Lagoa Feia e da Lagoa de Maricá-RJ. Disponível em: http://www.ebape.fgv.br/radma/doc/pop/pop-003.pdf. Acesso em 23 out 2007.

SERLA - Fundação Superintendência Estadual de Rios e Lagoas. Disponível em http//www.serla.rj.gov.br. Acesso em 23 out. 2007.

SOFFIATI NETO, A. A. DNOS: Uma instituição mítica da República Brasileira. Revista Brasileira de Estudos Urbanos e Regionais, v. 7, n. 2. Rio de Janeiro: ANPUR. Nov. 2005.

SOFFIATI NETO, A. A. O nativo e o exótico: perspectivas para a história ambiental na ecorregião NorteNoroeste fluminense entre os séculos XVII e XX. Rio de Janeiro: UFRJ. 1996.

VARGAS, Getúlio. A Nova Política do Brasil III. Rio de Janeiro: José Olympio. 1938, 306p.

WEBER, William (coord.). Ambiente das águas no Estado do Rio de Janeiro. Rio de Janeiro: SEMADS, 2001. 